\title{
Computer Aided Optimisation of the Design of the Hydraulic Slide Valve - Valve Body Fit
}

\author{
Tudor Deaconescu ${ }^{1}$ and Andrea Deaconescu ${ }^{2}$
}

\begin{abstract}
Diminution of volume losses of hydraulic valves can be achieved by the adequate selection of the type of fit of valve body and sliding element, that is by correct selection of the radial clearance. In the present paper, selection of the optimum fit type is achieved by the probabilistic mode, by imposing a limit value for the fluid leakage flow rate. The selection of the optimum type of fit is achieved by means of a computer programme specially developed for this purpose.
\end{abstract}

Keywords - hydraulic slide valves, fluid leakage, clearance and tight fit

\section{INTRODUCTION}

The increase of pressures in hydraulic equipment, determined by the requirement of reducing overall size and weight per power unit and of improving dynamic performances (reduced inertia) has yielded the development of hydraulic valves capable of working at high pressures and resistant to the forces generated in the system. An important problem of hydraulic systems is also related to increasing operational efficiency, a desideratum achievable, inter alia, by decreasing friction forces and flow rate losses caused by flawed sealing.

Hydraulically actuated working equipment is affected by many causes that may generate failure, one of these being the behaviour of sealing systems. Research aimed at determining the causes for hydraulic actuation systems failure have revealed the sealing tribosystem being responsible for $44 \%$ of the problems occurring during operation [1], [2]. This high percentage gives cause for concern and calls for increased focus on the construction and behaviour of sealing systems, with a view on minimising failure rate.

For a sealing system to perform adequately it has to satisfy three conditions simultaneously: high durability, perfect sealing and minimum friction. Ensuring at the same time sealing and minimum friction are evidently contradicting requirements, as perfect hermetical sealing entails large contact forces, yielding on their turn significant friction. Such

Prof. Dr. Eng. Tudor Deaconescu ${ }^{1}$ is with Transilvania University of Brasov, Department of Industrial Engineering and Management, Bd. Eroilor 29, Romania, RO-500036 ((corresponding author's phone: 0040-268-477113; fax: 0040-268-477113; e-mail: tdeacon@ unitbv.ro).

Prof. Dr. Eng. Andrea Deaconescu ${ }^{2}$ is with Transilvania University of Brasov, Faculty of Technological Engineering and Industrial Management, Department of Industrial Engineering and Management, Bd. Eroilor 29, Romania, RO-500036 (phone: 0040-268-477113; fax: 0040-268-477113; email: deacon@ unitbv.ro). opposing requirements lead to a compromise-based selection decision of the sealing system. Thus, for example, high friction forces may be accepted where a perfect hermetic sealing is required. Other requirements, however, imposed on hydraulic actuation systems, like reducing energy consumption and increasing efficiency call for a decrease of the friction forces generated in sealing systems [2].

In the case of hydraulic slide valves the sealing between their body and sliding element is achieved contact-free, in order to minimize the friction forces. The utilisation of contact-free sealings entails less energy required for operation, high reliability in exploitation and cheaper maintenance of the product.

In hydraulic slide valves the fit formed between their body and sliding element is a loose one, diemnsioned such as to ensure simultaneously two contradicting requirements: easy displacement with minimum fluid loss.

The paper presents a working method that allows a swift selection of the optimum fit for the valve body - sliding element assembly, such as to satisfy simultaneously the two conditions mentioned above.

From the range of factors determining the market success of a product, the most important ones are its quality and the time elapsed between the conclusions of the marketing department and the launching of the product. These two factors lend themselves to optimisation via computer aided design of the product, by means of specially developed programme packages.

The paper presents such a programme, developed by the authors, intended for the optimisation of the design of slide valve - valve body fits.

\section{ThEORETICAL AsPeCTS CONCERNING THE SELECTION OF THE OPTIMUM FIT}

In the case of hydraulic slide valves, volume or flow rate losses are generated due to the clearance between the slide valve and the valve body bore, and which occur between the high and low pressure chambers. The maximum volume admitted for flow rate losses at rated working pressure must not exceed $10 \ldots 15 \mathrm{~cm}^{3} / \mathrm{min}$.

Fig. 1 presents the diagram of the fit formed by the slide of the hydraulic valve and the body it moves within. It has to be mentioned, that in order to avoid jamming or generation of a large radial clearance at large temperature variations, valve body and slide are manufactured from the same material: case- 
hardened steel [3].
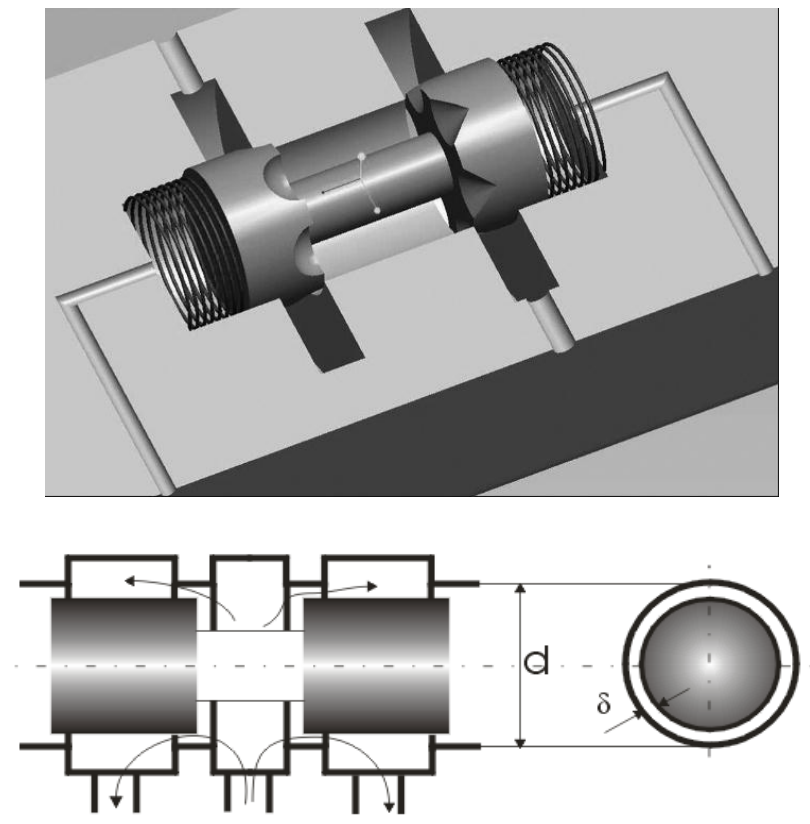

Fig. 1 Slide valve - valve body assembly

Selecting the actuation mode of slide valves entails determining the forces opposing the displacement of the mobile element (the silde). The actuation force of the slide needs to exceed the resisting forces, which include, inter alia, the friction force between the valve slide and the valve body, the hydrodynamic impulse force, the inertia force, and the force of the spring ensuring one of the slide's working positions.

The friction force between the slide and the body is of hydrodynamic type, depending not only on the geometrical characteristics of the assembly, but also on the roughness of the contacting surfaces and the precision of their machining. By increasing the radial clearance friction decreases, while, however, inadmissbily large volumetric losses occur in the slide valve.

The friction forces increase significantly with the occurremce of unbalanced radial forces, what can cause the blocking of the slide (hydraulic blockage). The occurrence of radial forces is a consequence of deviations from cylindricity of the slide and of the body, or of the deviations from parallelism of their axes.

The flow rate of fluid leakage due to flawed (radial clearance $\delta$ ) is computed with (1) [4]:

$$
\Delta Q=\frac{\pi \cdot d \cdot \delta^{3}}{12 \cdot \eta \cdot l} \cdot \Delta p
$$

where:

- $\mathrm{d}=$ slide diameter;

- $\delta=$ radial clearance;

- $\eta=$ dynamic viscosity of the sealed-off fluid;

- 1 = length of fit;
- $\Delta \mathrm{p}=$ pressure difference between the high and low pressure chambers, respectively.

In the particular case of a slide of diameter $\mathrm{d}=20 \mathrm{~mm}$, fit length of $0.4 \mathrm{~mm}$ and for $\Delta p=200$ bar, Fig. 2 shows the evolution of the leakage flow rate with an increasing radial clearance $\delta$ :

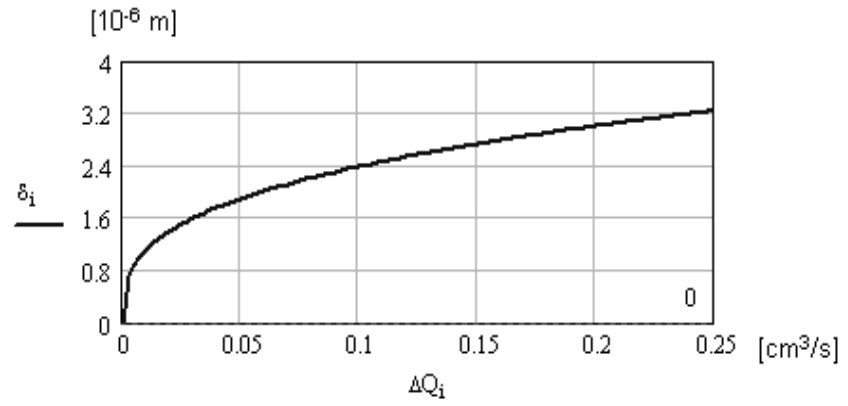

Fig. 2 Leakage flow versus radial clearance

The above diagram allows the conclusion that the radial clearance needs to be maintained within acceptable limits, such as to minimize fluid losses.

Considering the maximum admissible value of fluid leakage flow rate $0.25 \mathrm{~cm}^{3} / \mathrm{s}\left(15 \mathrm{~cm}^{3} / \mathrm{min}\right)$ and further that a $1 \mu \mathrm{m}$ is required in order to avoid the jamming of the piston, Fig. 2 allows the conclusion that the radial clearance can vary within the interval [1...3.236] $\mu \mathrm{m}$. Fulfilment of this condition suggests the selection of an intermediary fit, with a high probability for occurrence of effective clearances (> $97 \%$ ).

Fig. 3 highlights the characteristics of a loose fit. In this type of fit, the size limits for mating parts are selected such as to ensure a permanent clearance between them. To be noted that in a loose fit, the tolerance zone of the hole is entirely above the tolerance zone of the shaft. In a loose fit, the difference between the minimum size of the hole and the maximum size of the shaft is known as minimum clearance whereas the difference between the maximum size of the hole and minimum size of the shaft is called maximum clearance [5].

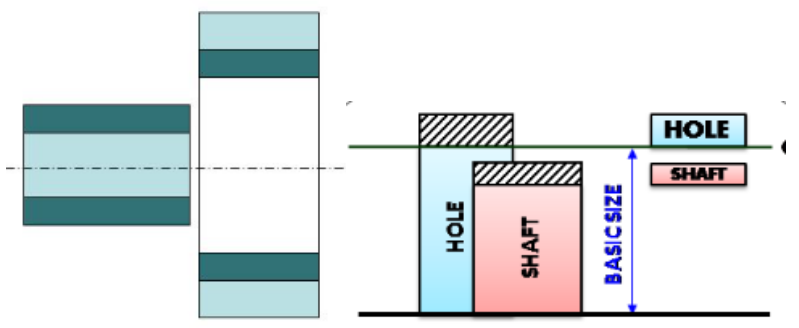

Fig. 3 Loose fit

It is known that in assembling shafts and bores manufactured to a certain precision, a fit is obtained of a higher practical precision (smaller practical tolerance), than the theoretically computed precision [6]. Considering the notations $T_{D}$ and $T_{d}$ for the tolerances of the bore and the shaft, respectively, the probable tolerance of the fit is given by (2): 


$$
T_{a j . p r}=\sqrt{T_{D}^{2}+T_{d}^{2}}
$$

Comparing the practical tolerance of the fit with the theoretical one, the former will be smaller, that is:

$$
T_{a j \cdot p r}=\sqrt{T_{D}^{2}+T_{d}^{2}}<T_{a j}=T_{D}+T_{d}
$$

An immediate consequence is that the practical limit clearances tight fits will be different from the theoretical ones, that is:

$$
\begin{gathered}
J_{\text {max } . p r}=J_{\max }-\frac{T_{a j}-T_{a j . p r}}{2} \\
S_{\text {max } . p r}=S_{\max }-\frac{T_{a j}-T_{a j . p r}}{2}
\end{gathered}
$$

where $J_{\max , p r}$ is the probable maximum loose fit, and $S_{\max , p r}$ is the maximum probable maximum tight fit.

The effective values of the clearance or tight fit in assembling are distributed by the normal law of Gauss-Laplace (Fig. 4).

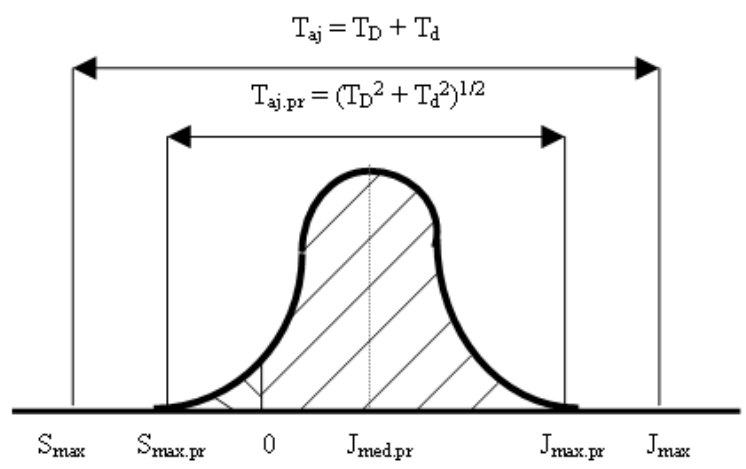

Fig. 4 Distributions of clearance and tight fit

The mean square deviation of the distribution shown in Fig. 4 is computed with (6):

$$
\sigma=\frac{S_{\max . p r}+J_{\max . p r}}{6}
$$

and the normed normal variable is:

$$
z=\frac{J_{\text {med }}}{\sigma}=\frac{J_{\max }-S_{\max }}{2 \cdot \sigma}
$$

where $J_{\max }$ and $S_{\max }$ represent the theoretical maximum clearance and tight fit, respectively.

The probability of obtaining the clearance is determined by (8):

$$
P_{J}=0,5+\frac{1}{\sqrt{2 \cdot \pi}} \cdot \int_{0}^{z} e^{-\frac{z^{2}}{2}} \cdot d z
$$

Considering the above equations, Table 1 presents four variants of fits, for a slide valve -valve body assembly with the rated diameter of $\mathrm{d}=20 \mathrm{~mm}$.

TABLE I

TYPE OF FIT

\begin{tabular}{|c|c|c|c|c|}
\hline Type of fit & H3/js2 & H2/js2 & H3/js3 & H3/js4 \\
\hline $\mathbf{J}_{\text {max.pr }}[\boldsymbol{\mu m}]$ & 4.358 & 3.0178 & 4.828 & 5.605 \\
\hline $\mathbf{P}_{\mathbf{J}}[\mathbf{\%}]$ & 99.45 & 98.31 & 98.31 & 95.2 \\
\hline Conclusion & YES & YES & YES & NO \\
\hline
\end{tabular}

It can be noticed that only the first three fits satisfy the two imposed conditions: $\mathrm{J}_{\text {max.pr }}<2 \cdot \delta=2 \cdot 3.236=6.472 \mu \mathrm{m}$ and a $\mathrm{P}_{\mathrm{J}}>97 \%$ probability of obtaining a convenient radial clearance.

\section{DedicAted COMPUter Programme}

The development of information systems has allowed management of large amounts of data, with an often inhomogeneous structure. In order to exploit these data, specialised instruments of data base management are employed, that ensure both elementary functions (introducing, modifying, recalling data, interrogations) and additional functions, like support for programming languages.

A dedicated application was devised for the swift determination of the optimum fit required for the silde valve valve body tribosystem. This programme was developed in Visual Basic.NET programming language, which allows the creation of data bases and of front-end type applications (at end-user level). The programme is aimed at designing the slide valve-valve body fit such as to limit the volume losses due to the clearance between the two elements to a maximum of $10 \ldots 15 \mathrm{~cm}^{3} / \mathrm{min}$.

The programme is designed in Wizard format, allowing the selection of the optimum type of fit by displaying a sequence of windows.

The first window (Fig. 5) displays the name of the programme, information related to the aim of the application and the link to the next phase. Another option is also the quitting of the application.

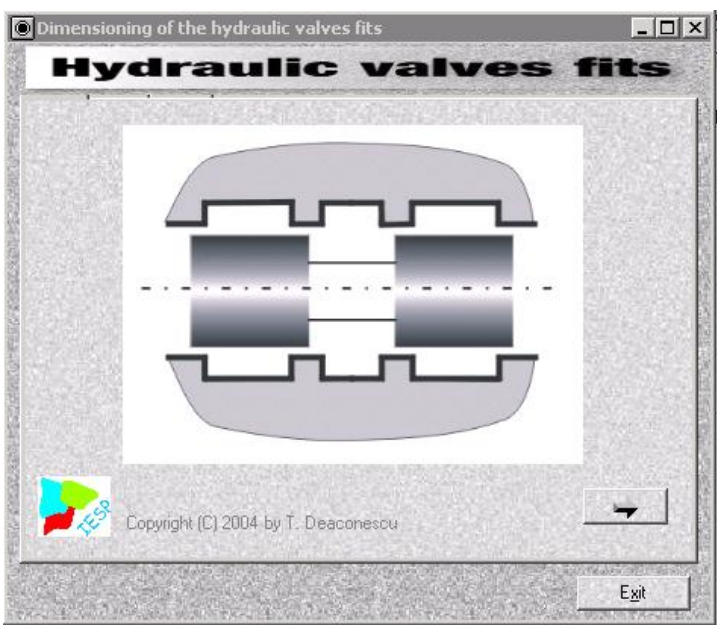

Fig. 5 Initial window of the programme 
The second window (Fig. 6) displays several options and requires the user to select appropriate values for each:

- selection of the interval of dimensions to comprise the rated dimension of the analyzed fit;

- selection - from a data base - of the fields of tolerance for the bore (valve body) and the shaft (slide valve).

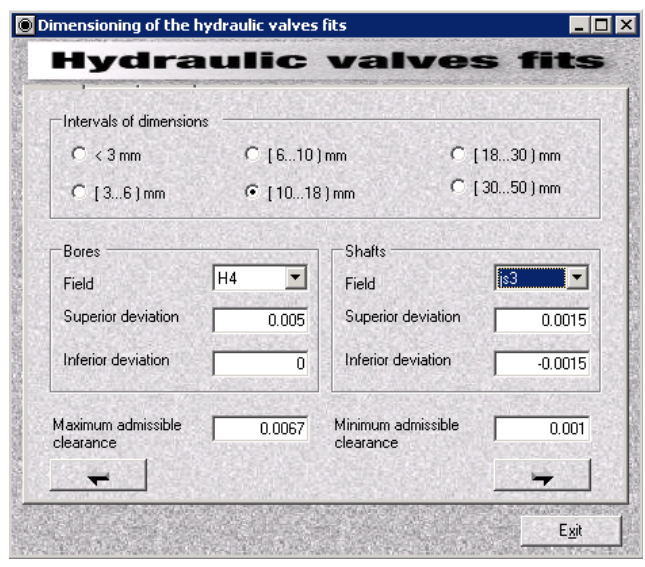

Fig. 6 Options window

The third window displays automatically the parameters of the fit (Fig. 7):

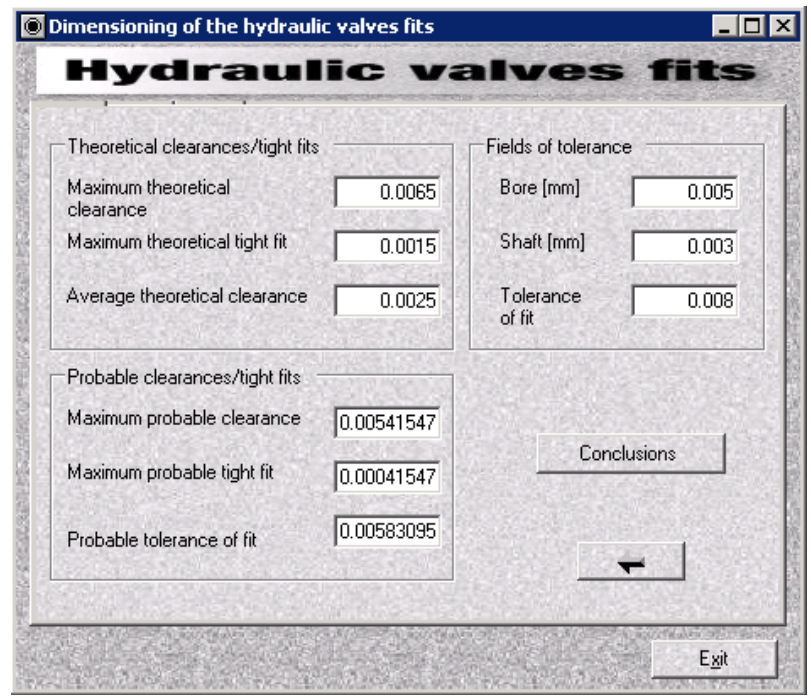

Fig. 7 Fit parameters window

Depending on the fields of tolerance selected for the slide valve and the valve body, respectively, the fourth window displays conclusions referring to the selected fit. Should the fit not satisfy the conditions related to minimum fluid loss, the programme displays the window of Fig. 8:

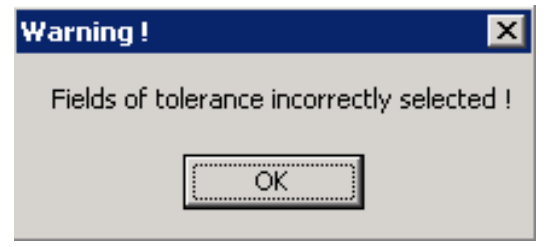

Fig. 8 Error message: wrong fit selected
In this case the user returns to the options window (Fig. 5) in order to select different fields of tolerance.

If the fields of tolerance have been correctly selected, a confirmation message will be displayed, as in Fig. 9:

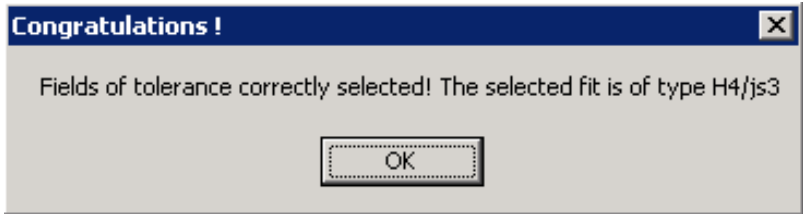

Fig. 9 Confirmation message: selection of a correct fit

\section{CONCLUSION}

The presented computer programme is a particularly useful instrument for designers of hydraulic drive systems, being applicable in various design situations, as for example in the selection of the fits of pistons and body of pumps with axial or radial pistons. The selection of an optimum fit is swift, simultaneously ensuring the achievement of minimum fluid loss.

\section{REFERENCES}

[1] A.Oprean, Hydraulic actuation and automation, Technical Publishing House Bucharest, Romania, 1983.

[2] T. Deaconescu, A. Deaconescu., "Film Thickness in Coaxial Sealing Systems of Hydraulic Cylinder Rods", J. of the Balkan Tribological Association, Vol. 20, No 3, 447-462, 2014.

[3] P. Gillella and S. Zongxuan, "Analysis and Synthesis of Spool Valves With Arbitrary Metering Area Variation", J. Dyn. Sys., Meas., Control 135(5), 054503, 2013. https://doi.org/10.1115/1.4024364

[4] M. Ivan, P. Maniut, I. Cristian, and G. Dobrea, Machine-tools Hydraulics. Transilvania University Publishing House, Brasov, 1989, pp. 167-171.

[5] "Mechanical Engineers Interview Questions", http://mechanicalengineeringinterivew.blogspot.ro/2015/09/blogpost.html Accessed: 12.09.2016.

[6] D. Dragu, G. Bădescu, A. Sturzu, C. Militaru, and I. Popescu, Tolerances and technical measurements, EDP Bucureşti, 1980.

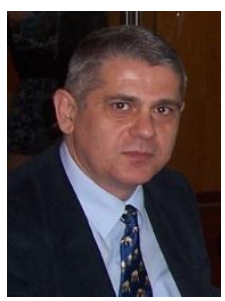

Tudor Deaconescu is a full professor at Transilvania University of Brasov, Romania. His main fields of competence are Quality Ensurance and Fluidic Actuations. He is the author of 13 books and over 170 scientifc articles.

Prof. Tudor Deaconescu is a member of a series of professional and scientific associations and is the director of the Festo National Research and Training Centre in Fluidic Drives and Automation in Brasov, Romania.

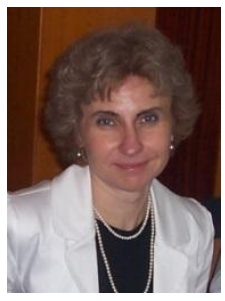

Andrea Deaconescu is a full professor at Transilvania University of Brasov, Romania. She obtained her $\mathrm{PhD}$ in Industrial Engineering at Transilvania University of Brasov, Romania in 2005 and an MA in Information Science at the University of Central England at Birmingham, UK. Her main fields of competence are Robust Design of Manufacturing Systems and Communication Management. She is the author of nine books and over 100 scientific papers. 